\title{
Early smoking initiation and nicotine dependence in a cohort of young adults
}

\author{
Naomi Breslau ${ }^{\mathrm{a}, \mathrm{b}}$, Nancy Fenn ${ }^{\mathrm{a}}$ and Edward L. Peterson ${ }^{\mathrm{a}}$ \\ Departments of Biostatistics and Research Epidemiology and Psychiatry ${ }^{b}$, Henry Ford Hospital, Detroit, MI and University \\ of Michigan, School of Medicine, Ann Arbor, MI (USA)
}

(Accepted February 16, 1993)

\begin{abstract}
We examined the extent to which nicotine dependence and daily smoking might vary by age at first cigarette. The potential confounding effects of sex, race and history of childhood behaviour problems were examined as well. A sample of 1200 was randomly selected from the subset of 21-30-year-old members of a large HMO in the Detroit SMSA; $1007(84 \%)$ agreed to participate. Personal interviews were conducted in respondents' homes, using the NIMH-DIS to elicit information on DSM-III$\mathrm{R}$ diagnoses, including nicotine dependence. Controlling for sex and race, persons who smoked their first cigarette at 14 to 16 years of age were 1.6 times more likely to become dependent than those who initiated smoking at an older age $(P=0.03)$. The association was unchanged when history of childhood behaviour problems was also controlled. Smoking initiation before age 14 was not associated with increased probability of dependence. Persons who initiated smoking before age 14 had a longer lag time to daily smoking and a lower likelihood of progressing to daily smoking, compared to persons who initiated smoking later on. The findings suggest that, among persons who have ever smoked, there might be two distinct groups in whom the chances of developing dependence are considerably reduced. The first comprises persons who delayed first use until age 17. The second comprises persons who smoked their first cigarette before age 14, a group in whom the progression to daily smoking might be markedly slower than in persons who initiated smoking when they were older.
\end{abstract}

Key words: nicotine; age of smoking initiation

\section{Introduction}

The potential for serious problems arising from the use of illicit drugs is greater for those who initiate use early in life than for those who initiate use later on (Robins and Murphy, 1967; Yamaguchi and Kandel, 1984; Robins and Przybeck, 1985; Kandel, 1989). The relationship between early smoking and nicotine dependence is unknown. There are data to suggest that early age of smoking initiation might be associated with a higher daily consumption of cigarettes and a longer duration of smoking in adulthood. (Taioli and Wynder, 1991; DHHS, 1982). Studies of adolescents reported positive associations be-

Correspondence to: Naomi Breslau, Ph.D., Department of Psychiatry, CFP-3 Henry Ford Hospital, 2799 West Grand Blvd, Detroit, M1 48202, USA. tween age and progression from first cigarette to second or third cigarette, or to current weekly smoking (Gaugh et al., 1982; Hirschman et al., 1984). None of these studies examined the association of age of smoking initiation with nicotine dependence. Information on the role of age of smoking initiation in nicotine dependence might have important implications for public health policy. Evidence that first use of cigarettes before a specified age signals an increased probability of nicotine dependence would suggest that efforts to delay the onset of smoking might lead to reductions in smoking related morbidity.

History of childhood behaviour problems was found to be a key predictor of early use of illicit drugs and the development of drug problems (Robins and Przybeck, 1985). Furthermore, strong associations were observed among mis- 
use of alcohol, use of illicit drugs, and delinquent behaviours in adolescence, an observation cited as empirical support for a syndrome with a common underlying basis (e.g., Donovan and Jessor, 1985). The role of childhood behaviour problems in nicotine dependence has not been previously investigated.

The purpose of this study was to examine the association of age of smoking initiation with nicotine dependence and onset of daily smoking. Data come from an epidemiologic study of young adults in the Detroit metropolitan area, in which DSM-III-R substance use disorders, including nicotine dependence, were ascertained. The study provides for the first time an opportunity to examine the association of age of first cigarette with nicotine dependence, as defined in the major psychiatric classification system. An additional purpose was to examine whether early smoking initiation, like early use of illicit drugs, was related to childhood conduct problems, and if an association between early smoking initiation and nicotine dependence was observed, to re-examine the association holding constant history of childhood conduct problems.

\section{Methods}

A sample of 1200 was randomly selected from all 21-30-year-old members of a 400000 member Health Maintenance Organization (HMO) in the Detroit metropolitan area. The HMO serves the tri-county area of Wayne, Macomb, and Oakland, which contains 3.9 million of the total 4.3 million of the Detroit SMSA. A total of 1007 respondents, $84 \%$ of the sample, were interviewed at their homes from March through October, 1989. The median age was 26 years; $61.7 \%$ were female; 80.7 were white and $19.3 \%$ were black. A minority, $3.7 \%$, had less than high school education, $21 \%$ had completed high school, $46 \%$ had some college education, and $29.3 \%$ were college graduates. Drawn from a list of members of a large HMO - subscribers and dependents - the sample represents the population of this age in the area, excluding the extreme of the socioeconomic range. (A more detailed description of the sample and comparisons of other HMO groups with the populations of their geographic areas are presented elsewhere) (Breslau et al., 1991).

\section{Measurement of key variables}

The National Institute of Mental Health Diagnostic Interview Schedule (NIMH-DIS) (Robins, Helzer, Cottler and Golding, 1989), revised to cover DSM-III-R diagnoses, was used to elicit information on lifetime psychiatric disorders, including nicotine dependence. The diagnostic definition of psychoactive substance use disorders in DSM-III-R reflects current consensus in the field of addiction on the cardinal features of substance use disorder (Rounsaville and Kranzler, 1989). At the core of the diagnosis is the construct of dependence, defined as a cognitive, behavioral and physiologic cluster that characterizes compulsive use of any substance. The diagnosis of nicotine dependence requires the presence of three of the following symptoms for at least 1 month: greater use than intended; unsuccessful efforts to control use; important activities given up; continued use despite social, psychologic or health problems; tolerance; withdrawal; and use to avoid withdrawal.

Age of smoking initiation was measured in all respondents who had ever smoked a cigarette and was defined as the age at which a respondent first smoked a cigarette, whether or not he or she continued to smoke. A positive history of childhood conduct problems was defined by one or more of the following behaviours before age 15: lying frequently, running away, starting fights, frequent problems at school because of misbehaviour,

frequent truancy, and school suspension or expulsion. These six items were selected from the list of 12 behaviour problems which define a history of childhood conduct disorder, required in DSM-III-R for diagnosing antisocial personality in adults. The NIMH-DIS was used to elicit information on these items.

\section{Statistical analysis}

The association between age of smoking initiation and nicotine dependence was examined by survival analysis. Kaplan-Meier survival analyses were performed, using the following three alternative definitions of age of smoking 
initiation: (1) $\leq 14$ vs. $\geq 15$; (2) $\leq 16$ vs. $\geq 17$; (3) $\leq 14,15-16$ and $\geq 17$. In each case, the survival curves of the compared groups crossed, indicating that the categories did not constitute internally homogenous, distinct groups with respect to the dependent variable, namely, nicotine dependence. Diagnostic plots of the log-log survival vs. log time indicated that the use of the Weibull survival model was appropriate (Lawless, 1982; SAS Institute Inc., SAS/STAT User's Guide, 1989). The Weibull survival model revealed a non-linear age relationship and suggested a three group categorization of age of smoking initiation $\leq 13,14-16$, and $\geq 17$ (see Figure in Appendix for details).

Using the Weibull model, we estimated ratios of time to dependence and ratios of the probability of becoming dependent (ratios of hazards) for age at first cigarette, defined by three categories, i.e. $\leq 13,14-16$ and $\geq 17$, with sex and race as covariates. We present these estimates, along with their $95 \%$ confidence intervals and their $P$ values from Wald $\chi^{2}$ statistics. The same technique was used to test the effect of childhood conduct problems on the association between age of first cigarette and dependence, and to estimate ratios of time from first cigarette to daily smoking.

\section{Results}

Nicotine dependence, smoking initiation and age of smoking initiation

Of the 995 respondents on whom complete data on smoking were available, $74 \%$ reported having smoked cigarettes in their lifetime. The prevalence of nicotine dependence among persons who had ever initiated smoking was $27 \%$, yielding a lifetime prevalence of nicotine dependence in the total sample of $20 \%$. Males and females had nearly identical rates of smoking initiation and nicotine dependence. The rates in whites were markedly and significantly higher than in blacks: $78 \%$ of whites vs. $58 \%$ of blacks initiated smoking $\left(x^{2}=29.9, P<0.0001\right)$, and $23 \%$ of whites vs. $8 \%$ of blacks met criteria for nicotine dependence $\left(\chi^{2}=19.7 ; P<0.0001\right)$.

The mean age of smoking initiation in the 732 persons who had ever smoked was $14.8( \pm 3.2)$, with males reporting a slightly younger mean age than females (not significant). Whites initiated smoking more than 1 year earlier than blacks, $14.6( \pm 3.1)$ vs. $15.8( \pm 3.5)(t=3.68$, $P=0.0002)$. Of those who ever smoked, $35 \%$ had their first cigarette before age $14,40 \%$ at $14-16$, and $25 \%$ after 16 years of age.

\section{Age at first cigarette and nicotine dependence}

Before we present the results of the survival analysis, we display in Table I the lifetime prevalence of nicotine dependence by age of smoking initiation, using the cutoffs suggested in the Weibull survival model. These data inform about the relationship between age at first cigarette and nicotine dependence, without adjusting for the potential effect of censoring. The lifetime prevalence of nicotine dependence was the highest in those who initiated smoking at 14-16 years of age, and the lowest in persons who delayed first use until age 17 or above.

In Table II appear the estimates of time to nicotine dependence and relative hazards associated with age of smoking initiation, with sex and race as covariates, from the Weibull survival analysis. Age of smoking initiation, measured as three discrete strata i.e., $\leq 13,14-16$, and $\geq 17$ - was significantly associated with nicotine dependence $(P=0.008)$. The association with sex was not significant. Race was significantly associated with dependence, with whites' to blacks' hazards ratio estimated at $1.9(P=0.01)$. Controlling for sex and race, persons who smoked their first cigarette at age 14-16 were 1.6 times more likely to become dependent than those who initiated smoking at an older age $(P=0.03)$. However, smoking initiation before

Table 1. Lifetime prevalence of nicotine dependence by age at first cigarettc.

\begin{tabular}{ll}
\hline Age 1st Cigarette & $\%$ Nicotine dependence \\
\hline$\leq 13(N=258)$ & 27.9 \\
$14-16(N=294)$ & 33.7 \\
$\geq 17(N=184)$ & 15.2 \\
\hline
\end{tabular}


Table II. Estimates of time to nicotine dependence and hazard ratios associated with age of 1st cigarette, with sex and race as covariates $(N=732)$.

\begin{tabular}{lllll}
\hline & $N$ & $\begin{array}{l}\text { Ratio of time to } \\
\text { dependence }\end{array}$ & Hazards ratio & $P$ value \\
\hline $\begin{array}{l}\text { Initiation age } \\
\leq 13\end{array}$ & 256 & $0.94(0.52-1.67)$ & $1.05(0.67-1.64)$ & 0.82 \\
$\begin{array}{l}14-16 \\
\geq 17\end{array}$ & 292 & $\begin{array}{l}0.53(0.30-0.93) \\
\text { Reference }\end{array}$ & $1.63(1.05-2.52)$ & 0.03 \\
$\begin{array}{l}\text { Sex } \\
\text { Male }\end{array}$ & 184 & $1.12(0.76-1.53)$ & $0.92(0.69-1.23)$ & 0.57 \\
Female & 453 & Reference & & \\
$\begin{array}{l}\text { Race } \\
\text { White }\end{array}$ & 623 & $0.42(0.22-0.84)$ & $1.92(1.14-3.25)$ & 0.01 \\
Black & 109 & Reference & & \\
\hline
\end{tabular}

Estimates from Weibull parametric survival analysis $(P$-value for age at 1st cigarette $=\overline{0.008})$.

14 years of age did not significantly increase the chances for nicotine dependence, compared to smoking initiation at $\geq 17$ ycars of age $(P=0.82)$.

Childhood conduct problems, age of smoking initiation, and nicotine dependence

To examine the relationship between early smoking initiation and childhood conduct problems, we present in Table III the rates of six childhood conduct problems across the three age of smoking initiation groups and the group of never smokers. Persons who initiated smoking $\leq 13$ had the highest rate of each of the conduct problems, and the highest rate of history of one or more conduct problems. Odds ratios for his- tory of one or more conduct problems in persons who initiated smoking $\leq 13$ vs. the two older smoking initiation groups and never smokers ranged from $2.0(95 \% \mathrm{CI} 1.4-2.8)$ to $2.4(95 \% \mathrm{Cl}$ $1.7-3.4)$. In contrast, persons who initiated smoking at 14-16 - the age range with the greatest probability of progression to dependence - did not have significantly higher rates of childhood conduct problems, compared to persons who initiated smoking later on or never smoked.

Using survival analysis to predict nicotine dependence, we found that history of childhood conduct problems did not have a statistically significant interaction with age of smoking initiation. We present in Table IV the survival model

Table III. Early ( $\leq 15$ ) conduct problems by age of smoking initiation.

\begin{tabular}{|c|c|c|c|c|c|c|}
\hline \multirow[b]{2}{*}{$(N)$} & \multicolumn{6}{|c|}{ Rate $/ 100$} \\
\hline & $\begin{array}{c}\leq 13 \\
(256)\end{array}$ & $\begin{array}{l}14-16 \\
(292)\end{array}$ & $\begin{array}{c}\geq 17 \\
(184)\end{array}$ & $\begin{array}{l}\text { Never } \\
(259)\end{array}$ & Chi-square & $P$ value \\
\hline Expelled/Suspended & 19.4 & 10.9 & 9.2 & 8.1 & 18.6 & $<0.0001$ \\
\hline Starting fights & 31.8 & 21.1 & 20.6 & 18.9 & 14.7 & 0.002 \\
\hline Truancy & 26.4 & 17.0 & 16.3 & 11.6 & 20.1 & $<0.0001$ \\
\hline Running away & 5.4 & 1.4 & 3.8 & 1.5 & 10.5 & 0.015 \\
\hline Trouble at school & 17.1 & 8.5 & 7.1 & 6.6 & 21.7 & $<0.0001$ \\
\hline Telling lies & 18.2 & 14.3 & 13.0 & 12.0 & 4.6 & 0.208 \\
\hline One or more problems & 61.6 & 44.5 & 40.8 & 40.2 & 30.6 & $<0.0001$ \\
\hline
\end{tabular}

Results of seven independent cross-tabulations. 
Table IV. Estimates of time to nicotine dependence and hazard ratios associated with age of 1st cigarette, with early conduct problems, sex and race as covariates.

\begin{tabular}{|c|c|c|c|c|}
\hline & $N$ & $\begin{array}{l}\text { Ratio of time } \\
\text { to dependence }\end{array}$ & Hazard ratios & $P$ value \\
\hline \multicolumn{5}{|c|}{ Initiation age } \\
\hline$\leq 13$ & 256 & $1.09(0.61-1.95)$ & $0.93(0.60-1.46)$ & 0.76 \\
\hline $14-16$ & 292 & $0.55(0.31-0.97)$ & $1.57(1.02-2.43)$ & 0.039 \\
\hline$\geq 17$ & 184 & Reference & & \\
\hline \multicolumn{5}{|l|}{ Sex } \\
\hline Male & 279 & $1.16(0.79-1.69)$ & $0.89(0.67-1.19)$ & 0.44 \\
\hline Female & 453 & Reference & & \\
\hline \multicolumn{5}{|l|}{ Race } \\
\hline White & 623 & $0.42(0.21-0.83)$ & $1.94(1.14-3.29)$ & 0.01 \\
\hline Black & 109 & Reference & & \\
\hline \multicolumn{5}{|c|}{ Conduct Problems } \\
\hline Yes & 363 & $0.48(0.33-0.71)$ & $1.75(1.29-2.37)$ & $<0.001$ \\
\hline No & 369 & Reference & & \\
\hline
\end{tabular}

Estimated from Weibull Parametric analysis ( $P$ value for age at 1st cigarette 0.003$)$.

to which we added history of conduct problems (yes/no), deleting the interaction terms. The probability of nicotine dependence was significantly higher in persons with a history of childhood conduct problems than in those with no such history. However, adjusting for the effect of childhood conduct problems (in addition to sex and race) did not change the previous estimates of the association between age of smoking initiation and dependence, as an inspection of Tables II and IV reveals.

Age of smoking initiation and the progression to daily smoking

We examined in Table $\mathrm{V}$ the lag time from first cigarette to the onset of daily smoking across the three age of smoking initiation categories. We postulated that smoking initiation at a very early age might be associated with a longer lag time to daily smoking, because of the lack of supportive or permissive social environment for smoking by young children. Age of smoking initiation was divided into single year groups, beginning with age 12 and ending with 18 , with those who initiated smoking before age 12 combined into a single category. In accord with our expectation, the time from first cigarette to daily smoking was longer in those who initiated smoking before age 14 than in those who initiated smoking later on, 3-4 years vs. 2 years or less.

Using survival analysis to estimate the ratios of time to daily smoking, we found that smoking initiation before age 14 was associated with the longest time to daily smoking. Ratio of time to daily smoking associated with smoking initiation before age 14 rclative to $\geq 17$ was $2.2(95 \% \mathrm{CI}$ $1.3-3.6)(P=0.002)$. The corresponding odds for progressing to daily smoking, estimated by

Table V. Age of smoking initiation and progression to regular smoking (daily smoking $\geq 1$ month).

\begin{tabular}{rrllll}
\hline $\begin{array}{l}\text { Smoking } \\
\text { initiation }\end{array}$ & & & \multicolumn{2}{l}{ Regular smoking } \\
\cline { 1 - 2 } Age & $N$ & & $\begin{array}{l}\text { \% of } \\
\text { Initiators }\end{array}$ & Mean age & S.D. \\
\hline$<12$ & 76 & 49 & 15.0 & 3.1 \\
12 & 80 & & 50 & 16.0 & 2.9 \\
13 & 102 & & 51 & 16.0 & 2.5 \\
14 & 88 & 51 & 16.0 & 1.7 \\
15 & 95 & 59 & 17.0 & 1.6 \\
16 & 111 & 62 & 18.0 & 1.9 \\
17 & 61 & 49 & 18.5 & 1.5 \\
18 & 50 & 52 & 18.5 & 1.0 \\
\hline
\end{tabular}


the hazard ratio, was $0.6(95 \%$ CI $0.5-0.9)(P=$ $0.002)$. The estimates for persons who initiated smoking at $14-16$ years of age vs. $\geq 17$ were near unity $(P=0.93)$. Thus, persons who smoked their first cigarette before age 14 were less likely and slower to progress to daily smoking, relative to persons who smoked their first cigarette when they were older.

\section{Discussion}

The results of this exploratory analysis indicate that persons who initiated smoking at 14-16 years of age were 1.6 times as likely to become dependent as those who initiated smoking at a later age. The increased likelihood $o$ nicotine dependence in persons who initiated smoking at 14-16 was not accounted for by childhood history of conduct problems, although such a history was associated with greater chances of becoming nicotine dependent. Contrary to the expectation that the earlier the age of smoking initiation, the greater the chances for dependence - an expectation based on studies of illicit drug use - persons who initiated smoking before 14 years of age were not more likely to become dependent, relative to persons who initiated smoking after 16 years of age. Further, smoking initiation before age 14 was associated with a significantly extended lag time to (and lower odds for) daily smoking, compared to smoking initiation at an older age.

'The finding that time from first cigarette to daily smoking was longer in persons who initiated smoking before age 14 than at an older age might appear to be at variance with previous reports that the lag time between first cigarette and the progression of smoking did not vary by age at first cigarette (Baugh et al., 1982; Hirschman et al., 1984). However, the previous reports did not examine the progression to daily smoking, but instead focused on the progression to second or third cigarette or to weekly smoking.

The finding that, among young adults, whites had a higher rate of smoking than blacks is in accord with reports from the 1981 - 1983 Behavioral Risk Factor Surveys (Remington et al., 1985), and the 1985 data from the National Household Survey (NIDA, 1985). The racial pattern in young adults, according to these national data, is a reversal of the trend in older age brackets, among whom smoking is more common in blacks than in whites. Our epidemiologic study is the first one to report that among young adults the lifetime prevalence of nicotine dependence, as distinct from smoking, was higher in whites than in blacks (for details see Andreski and Breslau, 1993).

Available evidence on the reliability of reports of age at first cigarette and onset of weekly smoking by children and adolescents (Baugh et al., 1982) provides some support for the reliability of the data in this study of young adults. Nonetheless, like all data from cross-sectional retrospective studies, our data on age of smoking initiation and nicotine dependence are subject to recall errors. Longitudinal studies of adolescents would provide stronger data on the course of smoking from first cigarette to nicotine dependence. Several caveats about the generalizability of the results are also in order. First, because the sample was randomly drawn from a HMO population of one region, the findings might not apply to the uninsured segments of the population or to other regions. Second, the young age of the sample precludes inferences to older adults. Third, apart from the constraints imposed by the characteristics of the population represented in our sample, the findings must be viewed in light of the evidence that smoking trajectories vary across cohorts (Presson et al., 1984; Johnston et al., 1988; O'Malley et al., 1988). Estimates of the associations between age of first cigarette and nicotine dependence reflect, at least in part, cohortspecific distributions of age of smoking initiation, school and community norms about smoking by youth, availability of cigarettes, and other factors that influence the level of support for smoking in childhood and adolescence across communities and over time.

It should also be kept in mind that the cutoffs 
for age at first cigarette used in this analysis, although similar to the cutoffs in one of the a-priori linear models tested at the outset, emerged empirically in the exploratory analysis we undertook when none of the three a-priori models were supported in the data. Consequently, the results are suggestive and in need of replication. In particular, the unexpected finding that persons who initiated smoking at a very early age (i.e., $\leq 13$ ) might be protected from the excess probability of dependence associated with early (i.e., 14-16) relative to late (i.e., $\geq 17$ ) smoking initiation requires further testing.

A non-linear relationship between age of first cigarette and nicotine dependence, such as that suggested in the data, might be explained by our findings of variability in lag time from first use to daily smoking. Our data show that daily smoking was usually delayed until age 16 , and that those who initiated smoking at age 11,12 or 13 had a longer lag time to daily smoking than those who initiated smoking later on.
Establishing daily smoking might require conditions that do not become available before age 16 , when adolescents begin to drive, enter employment and earn money and, at the same time, become freer from adult supervision. Apart from the potential inhibiting effects of social environments on the progression of smoking in the very young, there is evidence that children's experience of smoking the first cigarette is more unpleasant when it occurs before grade seven or eight than at a later age (Hirschman ct al., 1984), a finding that is consistent with the lower rate of progression in the very young ( $\mathrm{McNeill}$ et al., 1987). Recent studies of tobacco 'chippers', defined as smoking at least 4 days/week but no more than five cigarettes/day, have underscored the need for research on the determinants of variability in the level of nicotine dependence among smokers (Shiffman, 1991). Little is known about the process by which external factors in smoking initiation interact with the reinforcing pharmacologic effects of nicotine, believed to be critical for dependence (McNeill et

\section{Ratio of Time to Dependence vs. Age of 1 st Cigarette}

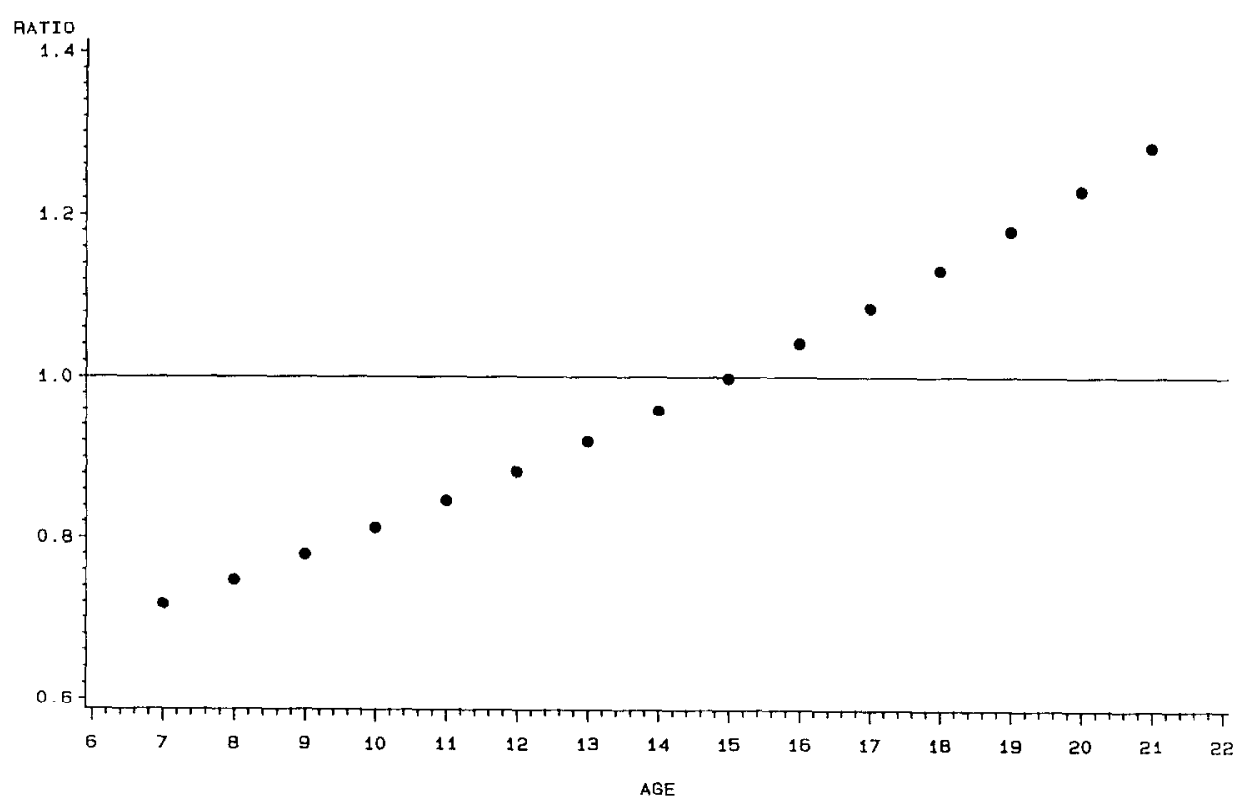


al., 1987; Shiffman, 1991). Longitudinal investigations of the potential effect of age of smoking initiation on the course of smoking might provide some answers.

\section{Acknowledgements}

This research was supported by a grant from Kingswood Hospital, Ferndale, MI, a research grant MH48802 and a Research Scientist Development Award $\mathrm{KO} 2 \mathrm{MH} 00380$ (Dr. Breslau) from the National Institute of Mental Health, Bethesda, MD.

\section{Appendix}

A Weibull survival model of time to nicotine dependence was fit, using as independent variables age at first cigarette (continuous), age-squared (centered around mean age), sex and race. Interactions among age of first cigarette, sex and race were not signficant $(P>$ $0.10)$. Age-squared had a significant effect on time to dependence $(P=0.03)$. The figure below displays the plot of the ratios of time to dependence at each age of first cigarette compared to the adjacent lower age, using parameter estimates from the Weibull model described above. The plot shows ratios $<1$ for persons who initiated smoking at age 13 or younger, $\sim 1$ for those who initiated smoking at 14-16 and $>1$ for those who initiated smoking at age 17 or older, suggesting the use of three groups of age of smoking initiation, namely, $\leq 13,14-16$ and $\geq 17$.

\section{References}

Andreski, P. and Breslau, N. (1993) Smoking and nicotine dependence in young adults: Differences between blacks and whites. Drug Alcohol Depend. 32, 119-125.

Baugh, J.G., Hunter, S., MacD, Webber, L.S. and Berenson, G.S. (1982) Developmental trends of first cigarette smoking experience of children: The Bogalusa Heart Study. Am. J. Public Health 72, 1161-1164.

Breslau, N., Kilbey, M.M. and Andreski, P. (1991) Nicotine dependence, major depression and anxiety in young adults. Arch. Gen. Psychiatry 48, $1069-1074$.

Donovan, J.E. and Jessor, E. (1985) The structure of prob- lem behavior in adolescence and young adulthood. $\mathrm{J}$. Consult Clin. Psychol. 53, 890-904.

Hirschman, R.S., Laventhal, H. and Glynn, K. (1984) The development of smoking behavior: Conceptualization and supportive cross-sectional survey data. J. Appl. Soc. Psychol. 14(3), 184-206.

Johnston, L.D., O'Malley, P.M. and Bachman, J. (1988) Illicit drug use, smoking and drinking by America's high school students, college students and young adults, 1975 - 1987. National Institute on Drug Abuse, US Dept. of Health and Human Services, Alcohol, Drug Abuse and Mental Health Administration. pp. 1-13. US Government Printing Office, Washington, DC, DHHS Publication No. (ADM) 89-1602.

Kandel, D.B. (1989) Issues of sequencing of adolescent drug use and other problem behaviors. Drugs Soc. $3(1-2)$, $55-76$.

Lawless, J.F. (1982) Statistical Models and Methods for Lifetime Data, Chapters 2,4 and 6, John Wiley \& Sons, New York.

McNeill, A.D., Jarvis, M. and West, R. (1987) Subjective effects of cigarette smoking in adolescents. Psychopharmacology 92, 115- 117 .

National Institute on Drug Abuse. (1988) National Household Survey on Drug Abuse: Main Findings, 1985, US Dept. of Health and Human Services, US Government Printing Office, Washington, DC, (ADM) 88-1586;

O'Malley, P.M., Bachman, J.G. and Johnston, L.D. (1988) Period, age and cohort effects on substance use among young Americans: a decade of change, 1976-86. Am. J. Public Health 78(10), 1315-1321.

Presson, C.C., Chassin, L., Sherman, S.J., Oshavsky, R., Bensenberg, M, and Corty, E. (1984) Predictors of adolescents' intentions to smoke: Age, sex, race and regional differences. Int. J. Addict 19(5), 503-519.

Remington, P.M., Forman, M.R., Gentry, E.M., Marks, J.S., Hogelin, G.C. and Trowbridge, F.L. (1985) Current smoking trends in the United States. The $1981-1983 \mathrm{Be}$ havioral Risk Factor Surveys. J. Am. Med. Assoc. 253, $2975-2978$.

Robins, L.N. and Przybeck, T.R. (1985) Age of onset of drug use as a factor in drug and other disorders. In: Etiology of Drug Abuse: Implications for Prevention. (Jones, C.L. and Battjes, R.J. eds.), pp. 178-192. NIDA Research Monograph 56. US Government Printing Office, Washington, DC, DHHS Publication No (ADM) $85-1335$.

Robins, L.N. and Murphy, G.E. (1967) Drug use in a normal population of young negro men. Am. J. Public Health 57, $1580-1596$.

Robins, L.N., Helzer, J.E., Cottler, L. and Golding, E. (1989) NIMH-Diagnostic Interview Schedule, Version III, Revised. Washington University, St. Louis, MO.

Rounsaville, B.J. and Kranzler, H.R. (1989) The DSM-III-R diagnosis of alcoholism. In: Review of Psychiatry (Tasman, A., Hales, R.E. and Frances, A.l., eds.), Vol. 8, pp. 323 -340. American Psychiatric Press, Washington, DC. 
SAS Institute Inc., SAS/STAT User's Guide, (1989) Version 6, 4th Edn., Vol. 2. pp. 997-1026. SAS Institute Inc., Cary, NC.

Shiffman, S. (1991) Refining models of dependence: variations across persons and situations. Br. J. Addict. 86, $611-615$.

Taioli, E. and Wynder, E.L. (1991) Effect of the age at which smoking begins on frequency of smoking in adulthood. N. Engl. J. Med. 325, 968-969.

US Dept. of Health and Human Services (1988) The Health Consequences of Smoking: Nicotine Addiction, Report of the Surgeon General. Office on Smoking and Health, Washington, DC, Publication CDC 88-8406.

US Dept. of Health and Human Services. (1982) The Health Consequences of Smoking: Cancer, a report of the Surgeon General, 1982. Government Printing Office, Washington, DC, DHSS Publication No. (PHS) $82-50179$.

Yamaguchi, K. and Kandel, D.B. (1984) Patterns of drug use from adolescence to young adulthood - III. Predictors of progression. Am. J. Public Health 74, 673-681. 